\title{
Analisis Beban Kerja Mahasiswa Praktikum Parasitologi Di Program Studi Ilmu Kesehatan Masyarakat Universitas Negeri Manado
}

\author{
I Wayan Gede Suarjana ${ }^{1^{*}}$ \\ 1) Program Studi Ilmu Kesehatan Masyarakat, Universitas Negeri Manado, Manado \\ ${ }^{*}$ e-mail: iwg.suarjana@unima.ac.id \\ doi: https://doi.org/10.24843/JEI.2020.v06.i01.p06 \\ Article Received: 12 Juni 2020; Accepted: 20 Juni 2020; Published: 30 Juni 2020
}

\begin{abstract}
Abstrak
Proses belajar mengajar di Program Studi Ilmu Kesehatan Universitas Negeri Manado diharapkan dapat terlaksana dengan baik tidak hanya secara teori melainkan juga saat praktikum. Praktikum yang dilaksanakan salah satunya yaitu praktikum parasitologi. Aktivitas praktikum dilaksanakan selama 4 sampai 5 jam. Pada akhir praktikum mahasiswa sering mengalami gejala pegal, kaku dan lelah dan ketelitian praktikum yang kurang baik. Kondisi ini perlu dilakukan perbaikan terhadap aktivitas selama melaksanakan praktikum, khususnya dilihat dari beban kerja mahasiswa. Oleh sebab itu dilakukan suatu penelitian secara eksperimental deskriptif dengan metode observasional kepada seluruh mahasiswa kelas A semester IV yang terdaftar pada mata kuliah praktikum parasitologi. Jumlah mahasiswa adalah sebanyak 25 mahasiswa. Beban kerja dianalisis dengan pengukuran denyut nadi, kondisi lingkungan kerja, kelelahan subjektif, gangguan muskuloskeletal dan Extra Calorie due to Peripheral Temperature (ECPT) dan Extra Calorie due to Peripheral Metabolism (ECPM). Lingkungan kerja yang diukur adalah suhu kering, suhu basah, kelembaban relatif, intensitas cahaya, dan kebisingan. Hasil penelitian diketahui bahwa beban kerja mahasiswa termasuk kategori sedang yang memerlukan intervensi lebih lanjut, kemudian terjadi peningkatan yang signifikan pada kelelahan subjektif dan keluhan otot skeletal sebelum praktikum dan sesudah praktikum. Oleh karena ECPM lebih besar dari ECPT maka perlu adanya perbaikan kondisi kerja yang berhubungan dengan aktivitas fisik mahasiswa yang mengacu pada kaidah-kaidah ergonomi, perbaikan sikap kerja, pengaturan waktu praktikum dan waktu istirahat, penyesuaian peralatan praktikum sesuai dengan antropometri mahasiswa, serta pengendalian lingkungan kerja.
\end{abstract}

Kata kunci: beban kerja, gangguan muskuloskeletal, kondisi kerja

\section{Workload Analysis on Parasitology Practicum Students at Public Health Study Program at Manado State University}

\begin{abstract}
Teaching and learning process at Public Health Studies Program at Manado State University was hoped can be carried out well not only in theory but at practical activity. One of the practicum that was carried out was parasitology practicum. Practical activities carried out for 4 to 5 hours. At the end of the practicum, students often experience symptoms such as feeling sore, stiff and tired and the lab accuracy was not good. This condition need to be corrected to the activities carried out during carrying out the practicum, especially from the workload of students. Therefore, a descriptive experimental study was carried out by the observational method to all students of Grade A semester IV enrolled in the parasitology practicum courses. The number of student were 25 students. The workload analysis was done by measurements of heart rate, environment conditions, subjective fatigue, musculoskeletal disorders and Extra Calorie due to Peripheral Temperature (ECPT) and Extra Calorie due to
\end{abstract}


Peripheral Metabolism (ECPM). The environment factors measured is dry temperature, wet temperature, relative humidity, light intensity, and noise. The results of the study show that the workload of students is moderate category that requires further intervention. There is a significant increase in subjective fatigue and musculoskeletal disorders before and after practicum. Because of ECPM is greater than ECPT, it is necessary to improve working conditions related to student physical activity that refers to the rules of ergonomics, improvement of work posture, adjustment the time of practicum and rest time, adjusting practicum equipment in according with student anthropometry, and controlling work environment.

Keywords: workload, musculoskeletal disorders, working conditions

\section{PENDAHULUAN}

Program Studi Ilmu Kesehatan Masyarakat (IKM) adalah Program Studi yang bernaung di bawah Fakultas Ilmu Keolahragaan Universitas Negeri Manado. Dalam upaya memaksimalkan belajar mengajar maka teknik pembelajaran dilakukan secara teoritik maupun praktik. Pembelajaran ini dilaksanakan untuk memberikan pengetahuan dan kompetensi mahasiswa sesuai dengan tujuan lulusan di Program Studi IKM Universitas Negeri Manado.

Praktikum dilaksanakan di ruang khusus sesuai dengan jenis mata kuliah yang memerlukan praktikum. Praktikum yang dilaksanakan salah satunya adalah praktikum parasitologi. Pada saat mahasiswa melaksanakan praktikum, praktik harus dilakukan dengan sikap kerja berdiri dan duduk sambil melakukan pengamatan menggunakan mikroskop. Hal ini terjadi karena dipengaruhi oleh sarana dan prasarana laboratorium dalam praktikum masih belum memadai. Mahasiswa harus beradaptasi dalam melakukan praktikum sesuai dengan sarana dan prasarana yang tidak memadai sehingga dapat memengaruhi tingkatan beban kerja fisik mahasiswa. Dalam tugasnya, mahasiswa diberikan tugas untuk melakukan pengamatan dan identifikasi parasit dan memerlukan waktu yang cukup lama serta perlu ketelitian untuk memperoleh hasil pengamatan dalam praktikum parasitologi. Saat mahasiswa melaksanakan aktivitas praktikum terjadi sikap kerja paksa berulang kali serta terjadi fleksibilitas tubuh seperti memuntir dan membungkukkan tubuh saat mencatat hasil pengamatan.

Selain sikap kerja berdiri statis disertai dengan posisi kerja membungkuk dalam kurun waktu yang cukup lama dapat terjadinya gangguan kesehatan mahasiswa yaitu terjadinya gangguan muskuloskeletal di bagian punggung, bahu dan leher, serta kelelahan subjektif pada mahasiswa. Praktikum biasanya dilakukan selama 4 hingga 5 jam sehari. Dalam kurun waktu yang lama tersebut dapat menimbulkan perubahan postur pada tubuh dan juga mengakibatkan kelelahan pada mahasiswa praktik. Hal ini dapat menyebabkan menurunnya performansi kerja yaitu ketelitian dan kualitas hasil pengamatan pada hasil praktikum mahasiswa.

Oleh sebab itu, maka diperlukan adanya evaluasi untuk memberikan solusi perbaikan dalam melaksanakan praktikum parasitologi. Untuk itu, perlu untuk dilakukan penelitian pendahuluan tentang analisis beban kerja pada mahasiswa praktikum di Program Studi IKM Universitas Negeri Manado sebagai dasar melakukan intervensi ergonomi dalam memperbaiki kondisi kerja mahasiswa. Tujuannya untuk mencari data awal perbaikan selanjutnya sehingga mutu pendidikan dan pembelajaran yang diselenggarakan dapat tercapai dengan baik berdasarkan perhatian pada kesehatan mahasiswa saat praktikum.

\section{METODE}

Penelitian ini merupakan eksperimental deskriptif dengan metode observasional. Responden penelitian adalah seluruh mahasiswa Kelas A Semester IV IKM yang terdaftar dalam mata kuliah praktikum parasitologi yaitu 25 orang mahasiswa. Beban kerja ditentukan 
dengan metode 10 denyut sebelum praktikum dan sesudah praktikum. Lingkungan kerja dan kelembaban relatif diukur dengan SmartThermo aplikasi Android. Kebisingan diukur dengan Sound Meter aplikasi Android. Intensitas Cahaya diukur dengan Lux Meter aplikasi Android. Keluhan subjektif dinilai dengan kuesioner kelelahan 30 item empat skala Likert, dan gangguan muskuloskeletal dinilai dengan kuesioner Nordic Body Map. Data dianalisis dengan statistik secara deskriptif terhadap beban kerja, gangguan muskuloskeletal, kelelahan subjektif dan Extra Calorie due to Peripheral Temperature (ECPT) dan Extra Calorie due to Peripheral Metabolism (ECPM) untuk mengevaluasi beban kerja mahasiswa.

\section{HASIL DAN PEMBAHASAN}

Hasil penelitian menunjukkan karakteristik mahasiswa IKM yang mengikuti praktikum parasitologi. Karakteristik mahasiswa praktikum parasitologi yang tersaji pada Tabel 1.

Tabel 1

Karakteristik Mahasiswa IKM

\begin{tabular}{clccc}
\hline No. & \multicolumn{1}{c}{ Variabel } & Rerata & Simpang Baku & Rentangan \\
\hline 1 & Umur (th) & 21,5 & 1,3 & $21-22$ \\
2 & Berat badan $(\mathrm{kg})$ & 53,3 & 3,4 & $44,9-62,1$ \\
3 & Tinggi badan $(\mathrm{cm})$ & 154,9 & 1,9 & $150-160$ \\
4 & IMT $(\mathrm{Kg} / \mathrm{m} 2)$ & 22,2 & 1,2 & $187,4-24,52$ \\
\hline
\end{tabular}

Berdasarkan hasil penelitian pada Tabel 1, dapat dijelaskan bahwa rerata umur mahasiswa 21,5 tahun dengan rentangan 21-22 tahun yang dimana merupakan umur produktif dan maksimal untuk masa studi. Rerata berat badan mahasiswa 53,3 kg yang berada dalam rentangan 44,9-62,1 kg. Rerata tinggi badan adalah 154,9 $\mathrm{cm}$ berada pada rentangan 150-160 $\mathrm{cm}$ ini menujukkan bahwa kondisi fisik mahasiswa dalam kategori ideal sampai dengan normal. Sedangkan rerata Indeks Massa Tubuh (IMT) mahasiswa adalah 22,2 Kg/m2. Rekomendasi IMT orang Indonesia untuk keadaan normal adalah antara 18-25. Jadi untuk IMT mahasiswa IKM peserta praktikum parasitologi berada pada kategori normal.

Lingkungan kerja merupakan suatu keadaan yang dapat mempengaruhi respon tubuh mahasiswa dalam beraktivitas secara langsung maupun tidak langsung. Kondisi lingkungan kerja laboratorium yang diukur ditunjukkan pada Tabel 2.

Tabel 2

Kondisi Lingkungan Kerja Praktikum

\begin{tabular}{clccc}
\hline No & \multicolumn{1}{c}{ Variabel } & Rerata & Simpang Baku & Rentangan \\
\hline 1 & Suhu Kering $\left({ }^{\circ} \mathrm{C}\right)$ & 24,15 & 1,45 & $23,05-25,94$ \\
2 & Suhu Basah $\left({ }^{\circ} \mathrm{C}\right)$ & 21,68 & 1,81 & $20,45-22,09$ \\
2 & Kelembaban relatif (\%) & 85,22 & 3,16 & $83,50-90,25$ \\
3 & Intensitas pencahayaan (lux) & 314,06 & 26,09 & $287,29-345,36$ \\
4 & Kebisingan (dB) & 83,72 & 5,83 & $79,58-87,25$ \\
\hline
\end{tabular}

Berdasarkan hasil pengukuran kondisi lingkungan kerja pada Tabel 2 menunjukan bahwa rerata suhu lingkungan ternyata belum memadai, karena suhu lingkungan yang nyaman untuk aklimatsasi orang Indonesia berada antara $24-28^{\circ} \mathrm{C}$ (Manuaba, 2008). Kelembaban relatif juga belum berada pada kisaran nyaman, dimana Manuaba (2008) menyatakan kelembaban yang diadaptasi oleh tubuh orang Indonesia berada pada kisaran $60-80 \%$. 
Intensitas pencahayaan yang didapat sebesar 314,06 lux ini berarti sudah terbilang memadai, karena menurut Margiono (2015) untuk area kegiatan meja dan mesin kerja ukuran sedang, proses umum dalam industri kimia dan makanan, kegiatan membaca dan membuat arsip tingkat penerangan yang direkomendasikan adalah 300 lux. Sementara itu kebisingan pada ruang praktikum sebesar $83,72 \mathrm{~dB}$ sudah memenuhi ambang batas tertinggi yang masih dapat diterima sesuai dengan Permenaker No 5 tahun 2018 tentang Keselamatan dan Kesehatan kerja Lingkungan Kerja.

Sutajaya dalam Indrasuari (2019) menyatakan perlu dilakukan perbaikan di lingkungan tempat kerja agar tidak berdampak negatit terhadap kualitas kesehatan, yang dilakukan dengan mengukur indikator lingkungan yang menentukan mikroklimat dan kenyamanan di tempat kerja. Kondisi mikroklimat lingkungan kerja yang tidak nyaman akan menimbulkan respon fisiologis diantaranya meningkatkan rasa lelah yang diikuti dengan hilangnya efisiensi kerja mental dan fisik, denyut nadi meningkat, tekanan darah meningkat, aktivitas alat pencernaan menurun, suhu inti tubuh meningkat, aliran darah ke kulit meningkat, dan produksi keringat meningkat.

Dilihat dari kondisi tersebut, maka seharusnya dilakukan evaluasi dalam perbaikan kondisi lingkungan kerja yang mengacu pada kaidah-kaidah ergonomi tentang lingkungan kerja fisik maupun non fisik. Dengan demikian energi mahasiswa yang terbuang akibat kondisi ruangan yang kurang nyaman bisa teratasi.

Untuk mengetahui beban kerja mahasiswa, maka dilakukan pengukuran kategori beban kerja berdasarkan denyut nadi menurut Grandjean seperti disajikan dalam Tabel 3.

Tabel 3

Kategori beban kerja berdasarkan denyut nadi

\begin{tabular}{clc}
\hline No & \multicolumn{1}{c}{ Kategori Beban Kerja } & Denyut Nadi Kerja (dpm) \\
\hline 1 & Sangat ringan & $60-70$ \\
2 & Ringan & $75-100$ \\
3 & Sedang & $100-125$ \\
4 & Berat & $125-150$ \\
5 & Sangat berat & $150-175$ \\
6 & Ekstrim & $>175$ \\
\hline
\end{tabular}

$\mathrm{dpm}=$ denyut per menit

Data beban kerja dihitung dengan metode 10 denyut/menit pada saat denyut nadi istirahat (DNI) untuk sebelum dimulainya kegiatan praktikum dan denyut nadi kerja (DNK) dilakukan pada saat sesudah melakukan praktikum, seperti tersaji pada Tabel 4.

Tabel 4

Denyut nadi mahasiswa

\begin{tabular}{ccccc}
\hline Variabel & Rerata $(\mathrm{dpm})$ & SB & $\mathrm{t}$ & $\mathrm{p}$ \\
\hline DNI & 68,07 & 5,88 & \multirow{2}{*}{$-22,426$} & \multirow{2}{*}{0,000} \\
DNK & 122,76 & 2,96 & & \\
\hline
\end{tabular}

$\mathrm{dpm}=$ denyut per menit

$\mathrm{SB}=$ Simpang baku

Dari Tabel 4, diketahui bahwa dari DNI ke DNK mahasiswa terjadi peningkatan yang signifikan. Dimana pada data denyut nadi kerja mahasiswa sebesar 122,76dpm. Jika data denyut nadi kerja mahasiswa dilihat dari Tabel 3 tersebut tergolong dalam beban kerja sedang 
pada interval $100-125 \mathrm{dpm}$. Ini membuktikan aktivitas praktikum yang dilakukan mahasiswa atau kondisi kerja yang berisiko terjadinya masalah kesehatan. Oleh sebab itu perlu nantinya dilakukan perbaikan kondisi kerja yang ditinjau dari kaidah-kaidah ergonomi sehingga dapat meminimalisir adanya kondisi kerja yang menyebabkan timbulnya penyakit akibat kerja.

Data gangguan muskuloskeletal yang diprediksi dengan menggunakan kuesioner Nordic Body Map 4 skala Likert dan kelelahan subjektif menggunakan kuesioner kelelahan 30 item disajikan pada Tabel 5.

Tabel 5

Gangguan Muskuloskeletal dan Kelelahan Subjektif

\begin{tabular}{llcccc}
\hline & & Rerata Skor & SB & t & p \\
\hline Gangguan & Sebelum Praktikum & 39,66 & 1,52 & \multirow{2}{*}{ Me,349 } & \multirow{2}{*}{0,000} \\
\multirow{2}{*}{ Kelelahan Subjektif } & Sesudah Praktikum & 82,03 & 3,51 & & \\
& Sebelum Praktikum & 34,41 & 1,24 & \multirow{2}{*}{$-24,601$} & \multirow{2}{*}{0,000} \\
& Sesudah Praktikum & 52,50 & 2,17 & \\
\hline
\end{tabular}

$\mathrm{SB}=$ Simpang Baku

Pada Tabel 5, menunjukkan bahwa antara sebelum praktikum dan sesudah praktikum terjadi peningkatan yang signifikan. Setelah praktikum gangguan muskuloskeletal yang dialami adalah 92\% mahasiswa merasa sakit di bagian bahu dan pinggang, 67\% mahasiswa merasakan sakit pada leher, lengan atas kanan dan kiri, serta sakit pada punggung. Kemudian kelelahan subjektif yang dirasakan oleh seluruh mahasiswa merasakan lelah di seluruh badan, nyeri pada punggung, dan merasa berat pada bagian kepala, kaki terasa kaku digerakkan, serta 60\% mahasiswa merasakan kaku bagian bahu. Apabila keadaan ini tidak diperhatikan dengan baik, maka akan berakibat buruk bahkan fatal pada kesehatan mahasiswa. Sikap kerja paksa atau tidak alamiah dalam rentang waktu cukup lama akan dapat menyebabkan timbulnya kelainan pada otot skeletal sehingga menimbulkan dampak negatif dari segi kesehatan mahasiswa. Sikap paksa pada saat mahasiswa melakukan praktikum disajikan seperti pada Gambar 1.

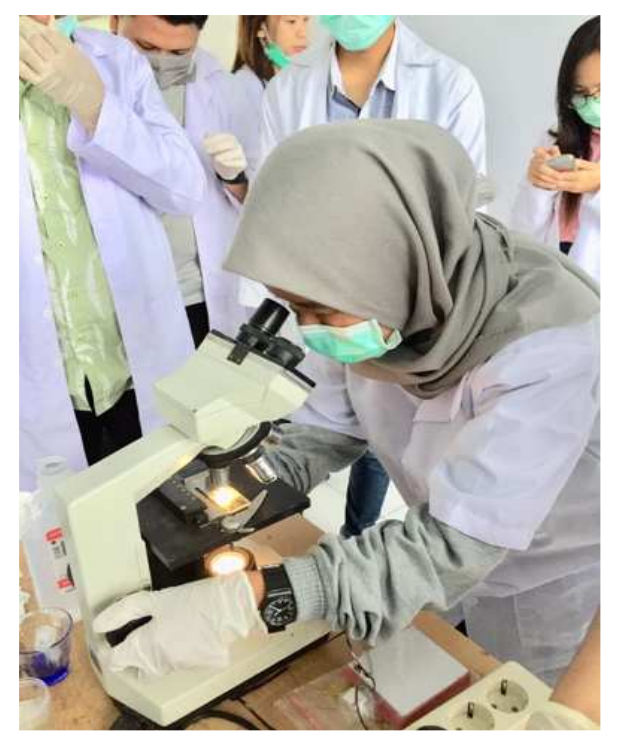

Gambar 1. Aktivitas praktikum

Kajian dari faktor lingkungan dengan menggunakan data ECPT dan ECPM dilakukan perhitungan yang disajikan dalam Tabel 6 . 
Tabel 6

Hasil Analisis ECPT dan ECPM

\begin{tabular}{lllcc}
\hline & Rerata & SD & t & $\mathrm{p}$ \\
\hline ECPT & 11,07 & 6,82 & -13.675 & 0,000 \\
ECPM & 15,85 & 5,01 & & \\
\hline
\end{tabular}

Dari Tabel 6 dapat dilihat bahwa nilai ECPM secara signifikan lebih besar daripada nilai ECPT yaitu nilai $\mathrm{p}<0,05$. Dari hasil tersebut dapat dilakukan evaluasi, apakah faktor tugas utama atau lingkungan yang lebih besar dalam mempengaruhi terjadinya beban kerja para mahasiswa. Menurut Adiputra (2002), serta Intaranont and Vanwonterghem (1993), apabila nilai ECPM lebih besar ECPT, berarti bahwa kerja fisik tugas yang dilakukan memang berat, sehingga upaya intervensinya ditujukan untuk menurunkan kerja utama.

Hal tersebut diakibatkan oleh aktivitas dan tugas mahasiswa dalam melakukan praktikum untuk mendapatkan hasil yang baik mahasiswa melakukan pengamatan dengan sikap kerja yang berulang dalam kurun waktu yang lama disertai aktivitas statis yang menimbulkan gangguan muskuloskeletal, dan kelelahan subjektif yang diakibatkan oleh sikap kerja paksa atau tidak alamiah. Oleh karena itu perlu adanya perbaikan kondisi kerja yang berhubungan dengan aktivitas fisik mahasiswa dalam praktikum dengan mengacu pada kaidah-kaidah ergonomi sehingga tidak menyebabkan timbulnya postur kerja paksa dan dapat mengurangi gangguan muskuloskeletal. Grandjean (1993) menyatakan bahwa sikap kerja paksa yang terlalu lama dapat meningkatkan beban pada sistem muskuloskeletal sehingga memberikan dampak negatif pada kesehatan manusia.

\section{SIMPULAN}

Dari hasil penelitian dan analisis maka dapat disimpulkan beban kerja pada mahasiswa praktikum parasitologi Program Studi Ilmu Kesehatan Masyarakat Universitas Negeri Manado termasuk dalam kategori sedang. Hasil penilaian gangguan muskuloskeletal dan kelelahan subjektif pada saat sebelum dan sesudah praktikum terjadi peningkatan yang signifikan $(\mathrm{p}<0,05)$. Oleh karena ECPM lebih besar dari ECPT maka perlu adanya perbaikan kondisi kerja yang berhubungan dengan aktivitas fisik mahasiswa yang mengacu pada kaidah-kaidah ergonomi yaitu perbaikan sikap kerja, pengaturan jam praktikum dan jam istirahat, penyesuaian peralatan praktikum sesuai dengan antropometri mahasiswa, serta pengendalian lingkungan kerja.

\section{DAFTAR PUSTAKA}

Adiputra, N. 2002. Denyut Nadi dan Kegunaannya dalam Ergonomi. Jurnal Ergonomi Indonesia, Vol. 3(1):22-26.

BSN. 2004. Nilai Ambang Batas Iklim Kerja (panas), kebisingan, getaran tangan-lengan dan radiasi sinar ultra ungu di tempat kerja. Badan Standarisasi Nasional. SNI 16-7063-2004.

Grandjean. 1993. Fitting the Task To the Man $\left(4^{\text {th }}\right.$ ed $)$. London: Taylor \& Francis.

Indrasuari. A.A.I.D. 2019. Peningkatan Beban Kerja Fisik dan Keluhan Muskuloskeletal Pada Petani Garam di Pantai Kusamba Klungkung Bali Tahun 2018.

Intaranont, K. dan Vanwonterghem, K. 1993. Study of Exposure Limit in Contraining Climatic Conditions for Strenous Task: an Ergonomic Approach. Final Report. Bangkok: Chulangkom University Department of Industrial Engineering. 
Manuaba, A. 1998. Bunga Rampai Ergonomi Vol. 1. Program Studi Ergonomi-Fisiologi Kerja . Denpasar: Universitas Udayana.

Manuaba, A. 2008. Ilmu Kebidanan, Penyakit Kandungan, dan KB. Jakarta: EGC.

Margiono A. 2015. Desain dan Instalasi Penerangan Lampu Jalan. Pontianak: Yayasan Kemajuan Teknik. 